\title{
IWRECKS PILOT SCENARIOS: REDUCING WASTE AND AVOIDING THE THREATENING OBSOLESCENCE IN ARCHITECTURE
}

\section{Stefanos Antoniadis *}

Department of Civil, Environmental and Architectural Engineering (ICEA), University of Padova, via Marzolo 9, 35131 Padova, Italy
Article Info:
Received:
16 March 2020
Revised:
8 June 2020
Accepted:
17 June 2020
Available online:
23 July 2020
Keywords:
Industrial wrecks
Decommissioned sheds
Architecture
Obsolescence
Transformation scenarios

\begin{abstract}
Obsolescence is something deeply linked to the production of waste, from the scale of small technological devices to the scale of urban stuff. The obsolescence of urban built environment, made by large buildings, vast areas, and even whole districts, is of course a more complex phenomenon to manage, if compared to the programmatic obsolescence of technological products. For this reason, intervening on the acknowledgment of the abandoned or decommissioned building, both in terms of highlighting a sort of heritage component and their reusing potentials, can mean a reduction in the number of buildings to be demolished and therefore in the production of rubble and waste. These topics have been dealt with in two research projects carried out at the University of Padova. The former (2017-2018), DATA_Developing Abandoned Transurban Areas ${ }^{1}$ aimed to propose sustainable future scenarios and develop ground-breaking strategies for the development and economic boost of scattered urban areas, focused on a territorial and urban scale to investigate effective regeneration practicability related to the location of the artefacts and the settlement situations around them. The latter (2018-2019), iWRECKS_Industrial Wrecks: Reusing Enhancing aCKnowledging Sheds ${ }^{2}$ essentially focused on the architectural scale aimed to provide innovative transformation visions to professionals, entrepreneurs, investors and citizens coping with the reuse of abandoned industrial buildings. Upgrading abandoned industrial sites and buildings has proved again to be a central issue in political and urban-focused debates in Italian north-eastern areas, particularly so in Veneto.
\end{abstract}

\section{INTRODUCTION}

The recent global economic crisis has worsened and highlighted the impact of shrinking productive activities such areas have been subjected to since the $90 \mathrm{~s}$. This has led to a "cumbersome" legacy as far as both the presence of useless over-built areas and economic losses are concerned: Veneto has been engulfed with increasingly empty and scarcely appealing industrial buildings, either owing to their being situated in suburban and rural areas, or to the poor quality as regards their construction-related, architectural and energy-efficient features.

According to the real estate report for the year 2019, published by the Territory Agency (Agenzia del Territorio, 2019), in Italy there are about 800,000 industrial buildings. Among them, about the $60 \%$ are located in the north part of the Country (Emilia-Romagna, Friuli-Venezia Giulia, Veneto, Liguria, Lombardy, Piedmont and Valle d'Aosta), while the remaining $40 \%$ is distributed in central, southern regions and islands. In Veneto Region 93,678 industrial buildings are estimated ( $12 \%$ of the whole national park), an amount that places Veneto as the second Italian region in industrial estate. In Veneto there are about 11,000 abandoned industrial buildings, accounting for about 3,9 billion euros of unused resources, rising to 7,9 billion if the satellite activities resulting from upgrading said buildings is to be reckoned (Confartigianato Veneto, 2017). Such data should be crossed with soil consumption, which in Veneto is the country`s highest: in 2013 8.4\% if compared with Italy as a whole (ISPRA, 2015).

Such industrial wrecks, clogging a slackening economic context, become a relevant challenge for an area that has always relied on productivity as its strong point - first concerning agriculture, later industry.

Notwithstanding the fact some moves may hint at a greater global awareness of the issue, if compared with the past, (the Regional Law concerning Soil Consumption ${ }^{3}$ is the latest, though not the only one), it is necessary to further activate suitable steps leading to positive assessment of the empties and to upgrading several impaired urban and environmental contexts. Regulatory and technical instruments should in fact be backed up by the ability to 
foresee the features of the buildings and the areas, to devise groundbreaking shapes, usages and functions so as to further the resorting to their precious spatial, social and economic resources anew.

\section{ACKNOWLED GING INDUSTRIAL STUFF}

In order to hope for and spark off a change in assessment and outlook (which is where projects start from when approaching unused or partially-used, end-of-life industrial and manufacturing buildings in suburban areas of modern towns), it is useful to construct (nay, to deconstruct) some wider arguments. Such arguments involve the perception and the awareness of shapes and relate to the cognitive abilities of people in general, not just of insiders or architects. Since the first stages of the analyses of the iWRECKS research project, during the first meetings with owners and stakeholders to sound their involvement and evaluate the case studies to be examined, the resort to different defining words by our counterparts has been noticed; only seemingly were they chosen unconsciously and automatically when referring to certain manufacturing buildings, storehouses and hangars. Some buildings were defined by their owners or by the ones in charge as "warehouses" or "storehouses", whereas others - quite indisputably - as "Cathedral" (for example one of the hangars of the $\mathrm{SIT}^{4}$ in North Padua ZIP), or "Basilica" (applied to the Legnago, near Verona, former Montedison storehouse). The same applies to the former Cattle Market of Padua ${ }^{5}$ (Figures 1, 2 and 3), located alongside Corso Australia ring road, though not examined in this research project; baptized by the local inhabitants "The Cathedral" (to tell the truth, it looks rather like a huge mosque than a cathedral, but this is another matter...), to the community and people's committees (there is even a Comitato Cattedrale Davanzo) it has become a recognizable urban fixture that should by all means be preserved, beyond and independently from often restrictive and counter-productive statutory environmental requirements.

Therefore, even before deciding by means of an architectural project to tamper with a building in order to prolong its shelf-life, it is obvious that well-known and established artefacts such as the Basilica or the Cathedral (there might even be the Tower, the Pyramid, the Cube and further wrecks simply not examined during this year of research) will be less liable to become obsolete. Actually, it sounds odd to refer to the pyramids of Giza as "former tombs", or to the Colosseum as a "former amphitheatre", or to the Eiffel Tower together with the wide mall stretching at its feet as a "former Expo area" (whereas immediately after the 2015 Milan Expo it was deemed necessary to set up the "Expo after Expo"6 nation-wide team of experts, heavens know why).

This unwillingness - underlined by the habit of resorting to the "former" prefix - to overcome the function and abstract the form of things, which end up being defined according to their functional call, leads to a corresponding inability of the buildings themselves to adapt to new features and new lives. In this strange - though easily under-

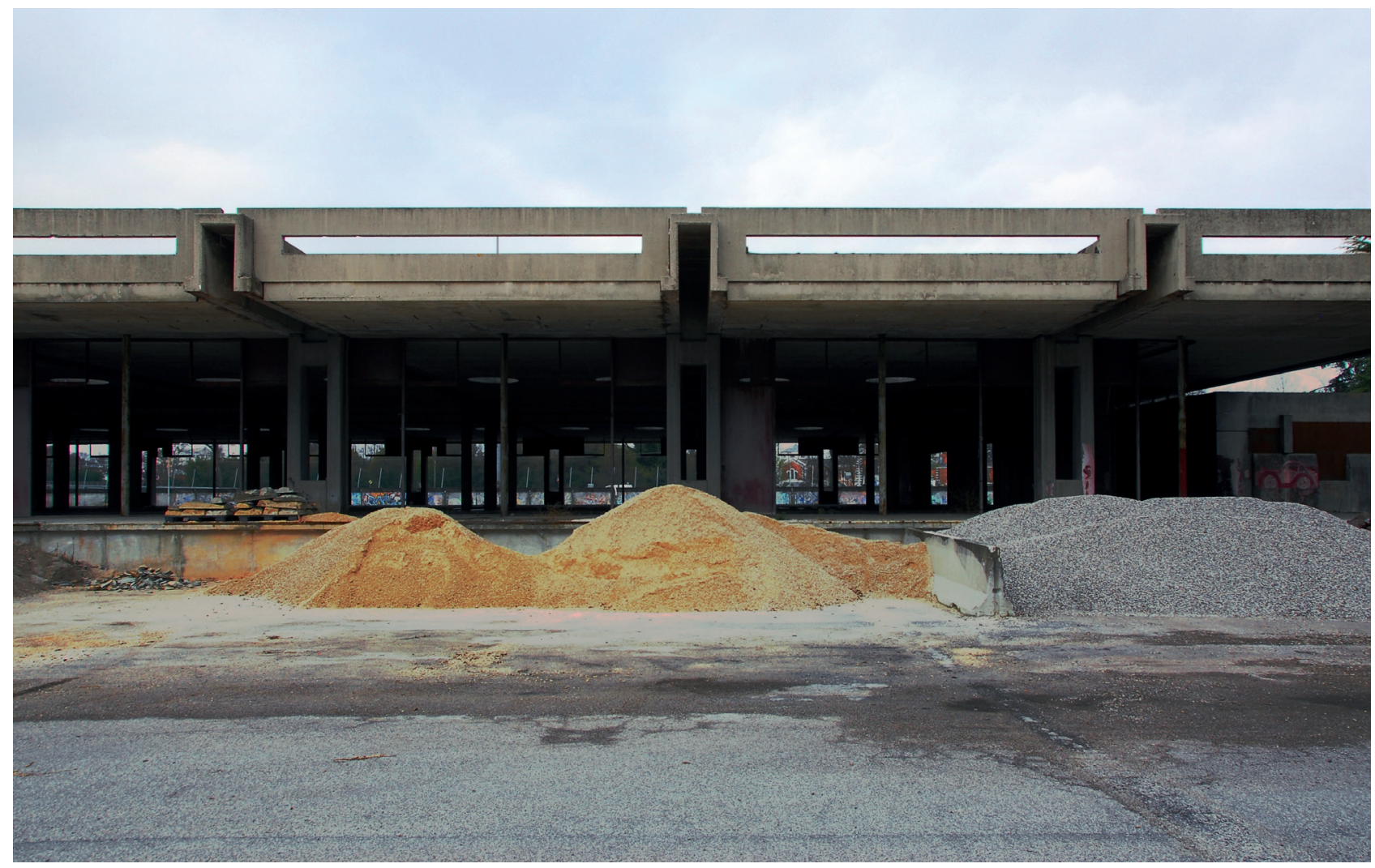

FIGURE 1: The former Slaughterhouse (1968) of Padua, Italy, by architect Salce, now infrastructure and road waste municipal storage (photo by S. Antoniadis, 2018). 


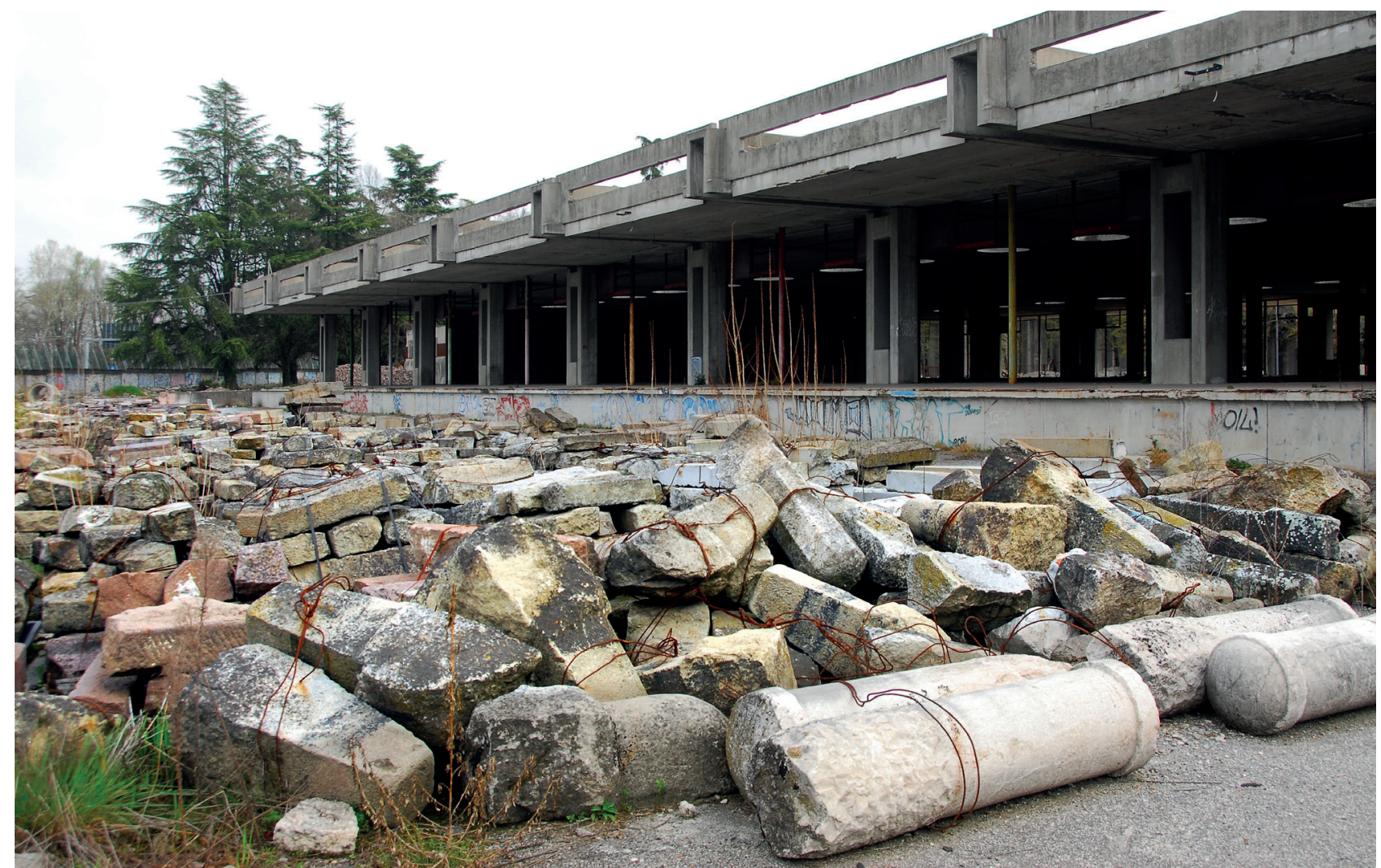

FIGURE 2: The former Slaughterhouse (1968) of Padua, Italy, by architect Salce, now infrastructure and road waste municipal storage (photo by S. Antoniadis, 2018).

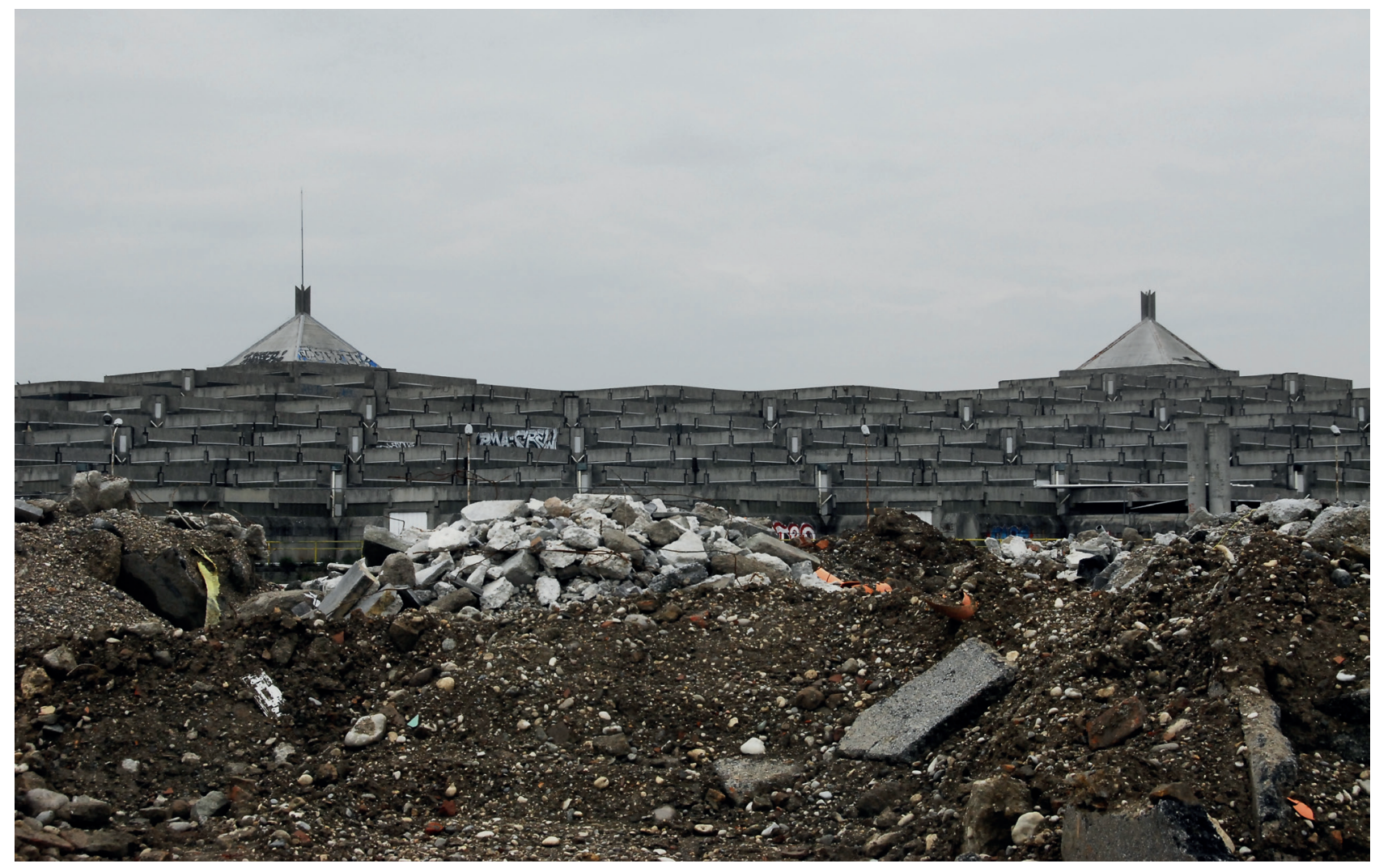

FIGURE 3: The Former Cattle Market ("The Cathedral”) of Padua (1965-68), by architect Davanzo, now infrastructure and road waste municipal storage (photo by Stefanos Antoniadis, 2012). 
standable - hypothesis formulated by Sapir-Whorf ${ }^{7}$ applied even to urban organisms, the destiny of buildings seems to be unsplittable from the language describing them, piling up cognitive and manipulative staples that condition any possible future re-purposing.

Re-purposing becomes in fact the typical solution for buildings and slices of town-areas no longer performing; it is in fact maintained that re-purposing should withstand the ticking forward of time. This research has tried to sug-
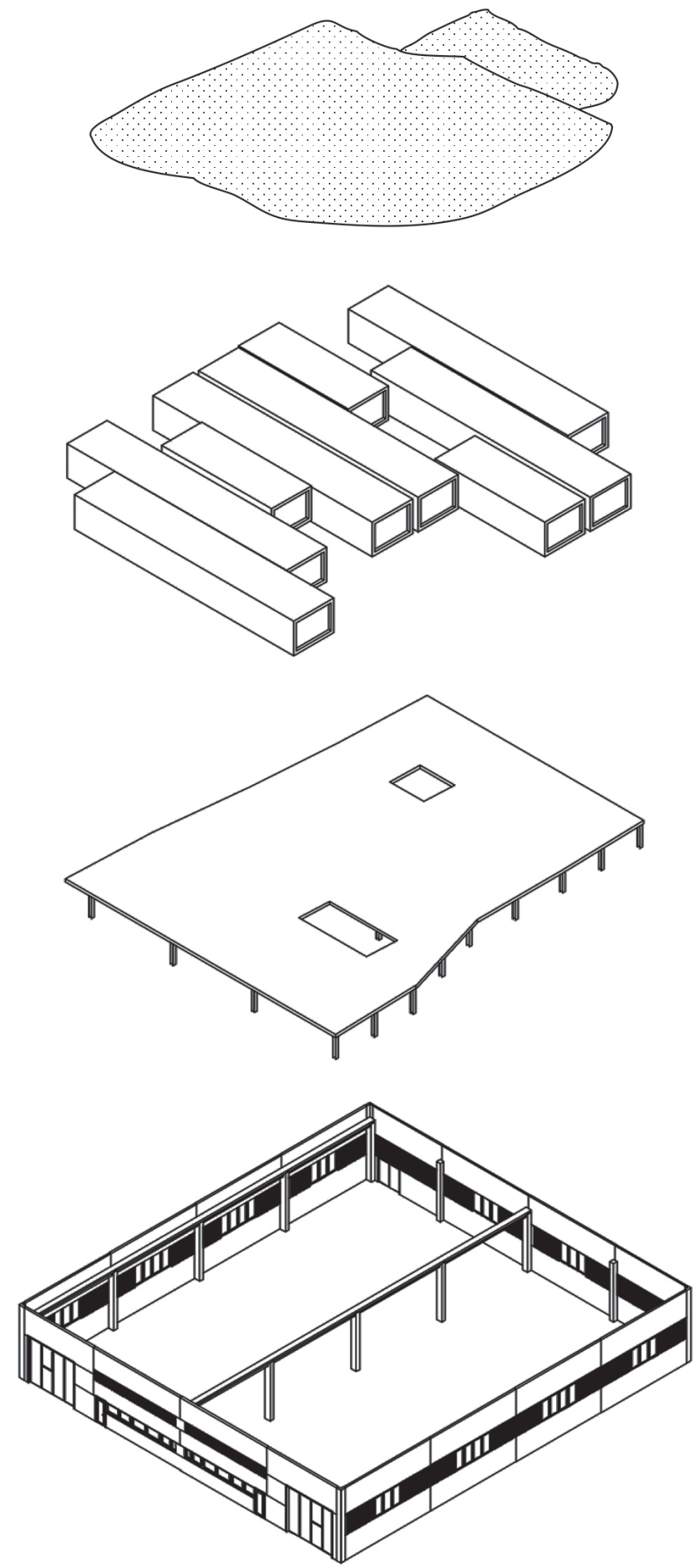

FIGURE 4: Formal elements for the industrial estate regeneration (scheme by iWRECKS, 2019). gest alternative approaches, namely the visualization of formal rather than functional categorizations.

Most of these industrial sheds were built starting from the post-war years using structural solutions able to guarantee large covered and easily adaptable spaces. According to the construction system, these warehouses can be classified in steel frame, precast or cast-in-site reinforced concrete structure. Sometimes prestressed precast concrete beams and masonry structures can be found too, but approximately the $80 \%$ of the Veneto region cases consists in the typical single-storey precast reinforced concrete buildings from the last decades (the constellation of small, medium and large "boxes" that dot the Po Valley landscape), eventually equipped with a mezzanine for offices.

The case studies selected exemplify both the different structural and material cases and various degrees of formal quality to highlight a complete suite of intervention criteria that could be usefully applied to broaden the range of options available: some belong clearly to the well-defined category of industrial archaeology (the Thiene end-of-theXIX-century Facchinetti former button factory), some are striking cast-in-place-concrete buildings (referring to the huge former Montedison storehouse in Legnago, near Verona), there are also the large areas taken by the 70 s vaulted sheds (the former Miralanza storehouses in the south part of the industrial district in Padua), the newly-devised small and medium-sized boxes of typical pre-fabricated sheds (one of the buildings of the SIT area in the north one) and the $\mathrm{AMAT}^{8}$. in the Veggiano industrial area in western suburbs of Padua) that prove to be the most widely present industrial buildings typology for the area.

The manipulations are meant to enact a new, flexible spatial set-up that can be applied in different ways, depending on the formal features of the context.

\section{FROM WASTE INTO RESOURCE}

Starting from the layout of the simple elements of the composition, an attempt has been made to analyse and organise them according to formal configurations consistently and suitably, depending on the case studies. The elements can accordingly be categorised as hollow parallelepids ( $S, M, L, X L$ boxes), either flat or folded planes, and heaps (i.e. mounds resulting from the piling up of suitably blanketed materials from demolitions and reclamations, which shape the features of the landscape anew), in order to identify a series of ad hoc (though at the same time flexible) strategies that may be applied beyond the case study (Figure 4).

Wherever buildings were high enough to allow double-height partitions, the choice has been to resort to a supporting floor on top of which the boxes were arranged, so as to employ two floors: the ground floor for services, the first floor serviced. An example can be the AMAT shed (Figure 5), but this also applies to most hangars throughout Italy. Precast roofing allows to obtain openings and patios by simply removing some elements (which has been suggested by surveying the state of decay of the hangar). The devised scenarios show how a quite ordinary set of pre-fabricated buildings can be transformed into a cluster 
of urban villas, or a lovely old-people home, or a school, or a co-working hub (Figures 6 and 7).

On the other hand, when the height forbids the creation of two habitable floors (for example the former Miralanza shed), the only floor can be reshaped creating lay-bies and shelves that can be easily turned into sports plates, skateboard tracks and $\mathrm{MTB}^{9}$ Park indoor and swimming pools (Figure 8); this is highly cost-efficient, since no digging is required (no waste material produced); the equipment lies on top of the ground: beneath are arranged the servicing

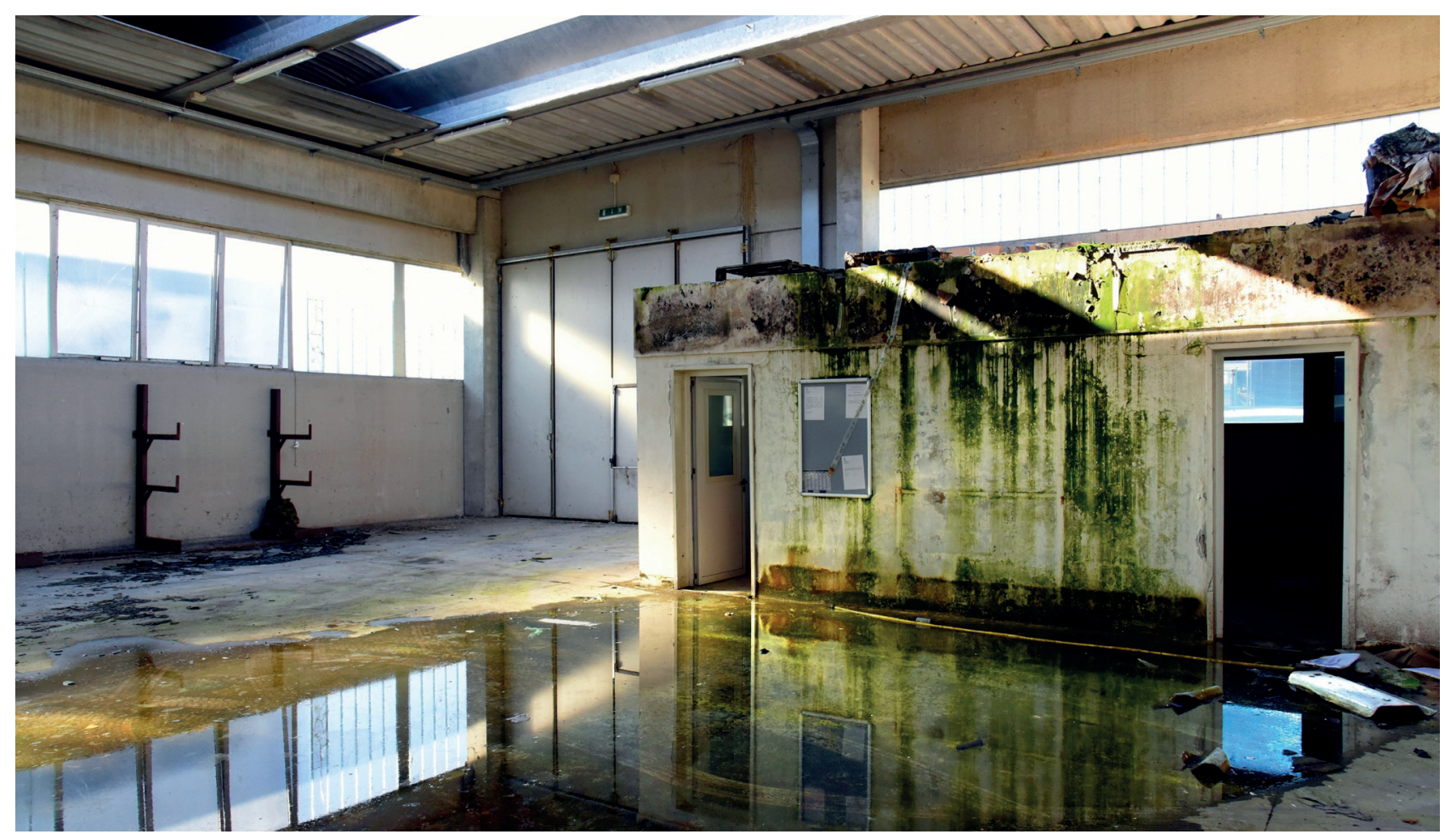

FIGURE 5: The AMAT shed in Veggiano, Padua, Italy (photo by S. Antoniadis, 2018).

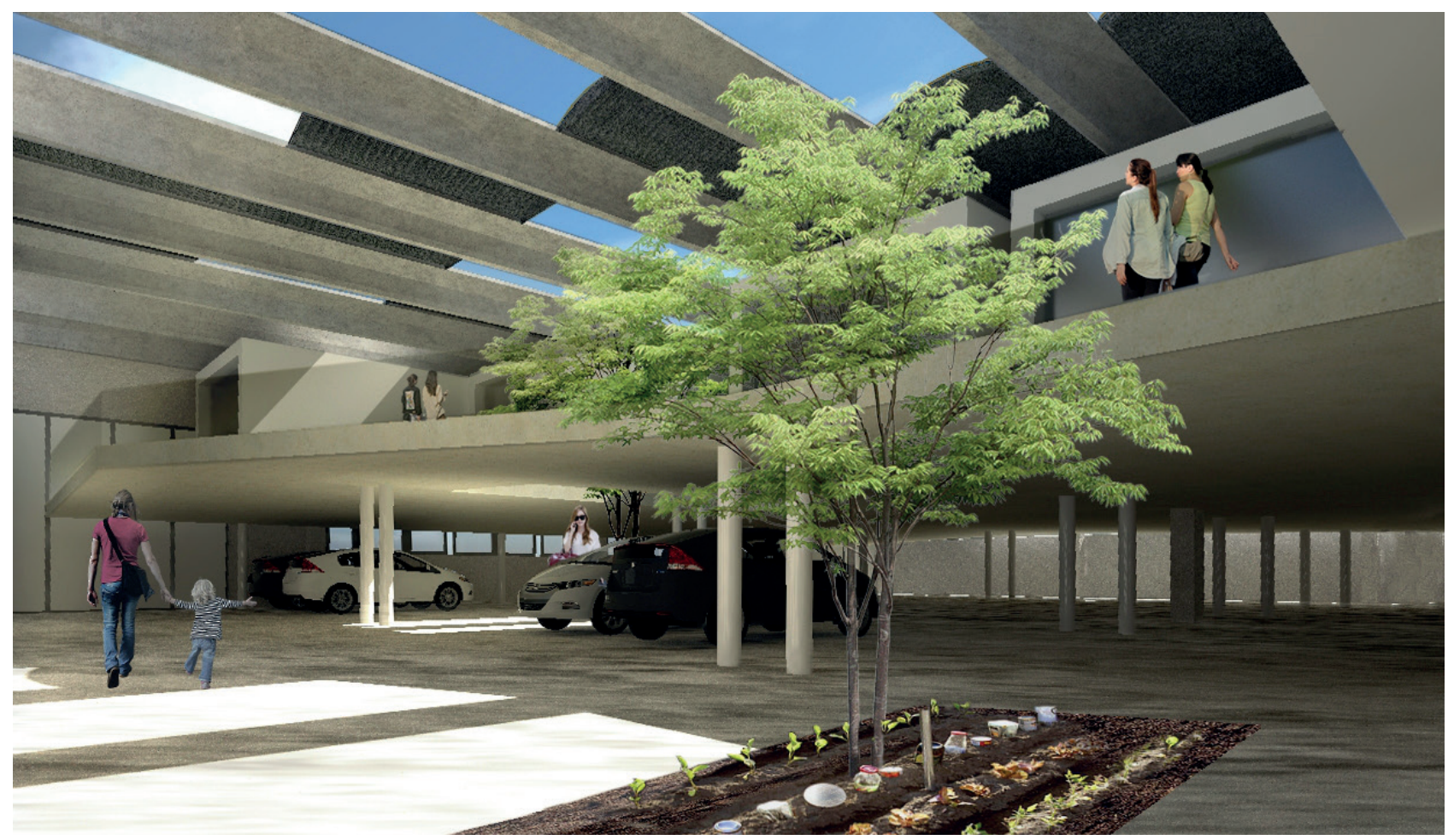

FIGURE 6: Transformation scenario for the AMAT shed (image by iWRECKS, 2019). 


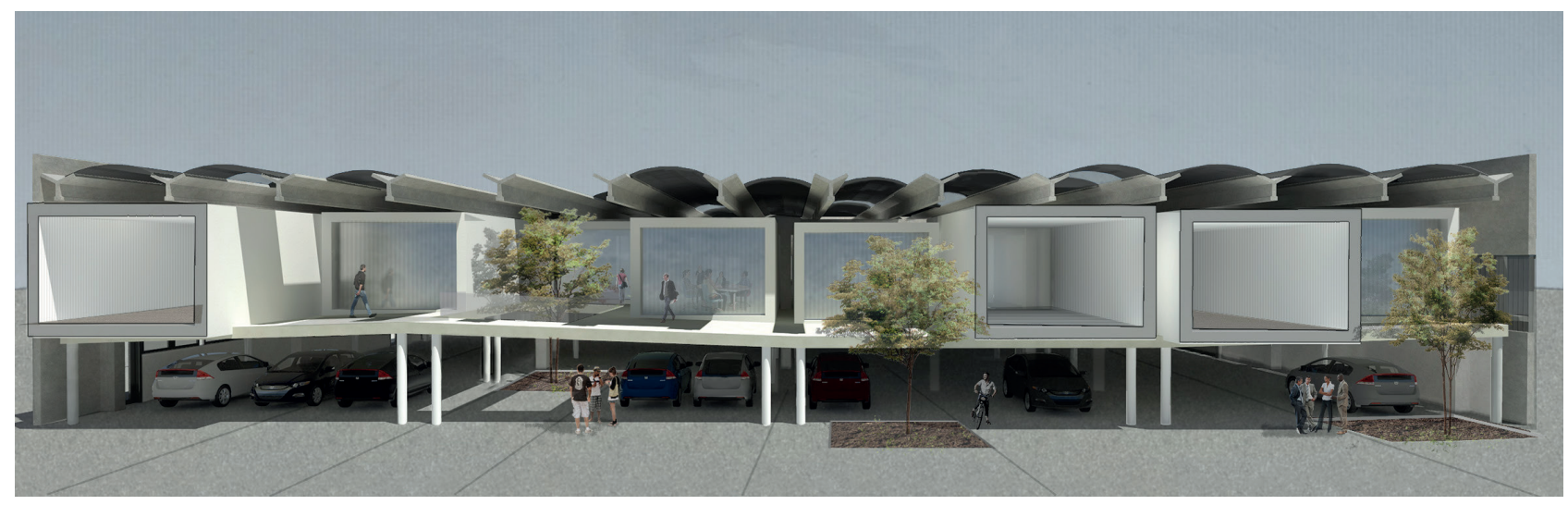

FIGURE 7: Transformation scenario for the AMAT shed; section (image by iWRECKS, 2019).
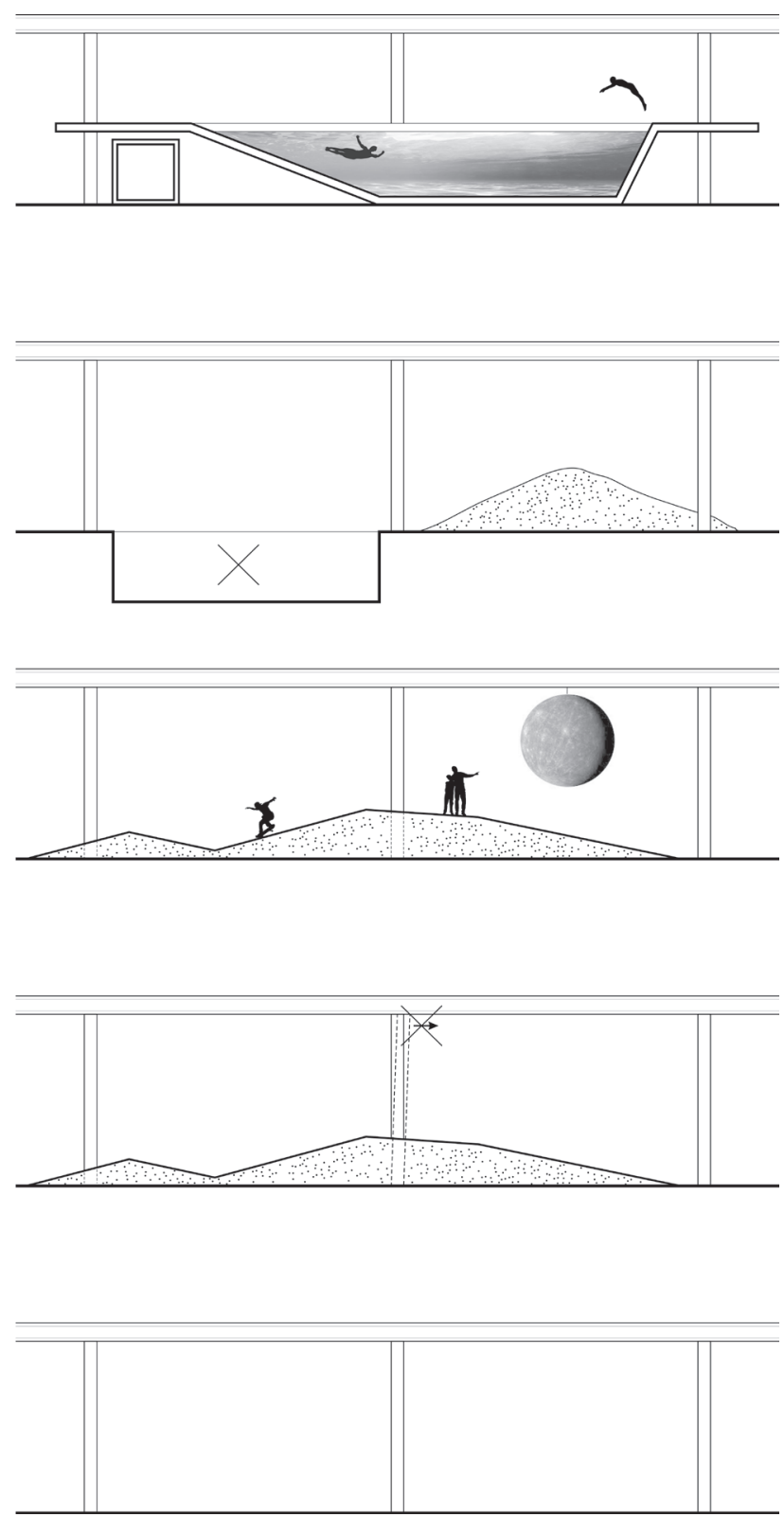

FIGURE 8: Formal, structural and waste management strategies applied to the typical industrial shed section (scheme by S. Antoniadis, 2019). box-like elements (locker-rooms, toilet facilities, technical and pump rooms, etc.) (Figures 9, 10, 11 and 12).

Whenever the height is suitable, instead, the aptly-distanced boxes can afford the use of space at various levels: reckoning the available volumetric dimensions, the useful surfaces can best be employed; besides, they can even afford suitable observation points when the available space is special and stately as in a basilica (e.g. the SIT hangar and the former Montedison storehouse) (Figures 13, 14, 15 and 16).

If the building is rather small and its structure irregularly-cut (the reference is Facchinetti former button factory), placing in it various box-like elements and planes would create a clutter - even from a spatial point of view - rather than provide a solution. Here the box-concept may aim for a different, much bigger range, somehow reversing the container-contents formula, by partially "encasing" the original blocks and tracing a clear-plastic envelope, a winter garden, a communal space to be enjoyed together with the rebirth of the wreck, according to the devised upgrading of functions.

\section{CONCLUSIONS}

Spreading and multiplying these manipulative opportunities to all those similar instances that can be identified in the field of survey (help is provided by creating a map of the buildings that can be converted on GIS database) is indeed possible to figure a scenario of sweeping innovation involving whole areas, so far mainly devoted to productive or industrial activities. These items, mainly regarded as atopic, commonplace, ugly ${ }^{10}$ and embarrassing, in their having become real stereotypes, have acquired the status of staple buildings, the target of systematic upgrading that can be easily shared. Uploading these multi-scalar and multi-criteria data in online platform such as the National Geoportal, the Regional ones or other territorial local offices webmaps could provide a sort of "transformability map" of the built environment to administrations and stakeholders' attention. An often only half-glimpsed potential that the research project, by elaborating new scenarios, means to bring to the notice of owners, decision-takers, law-makers and citizens, so 


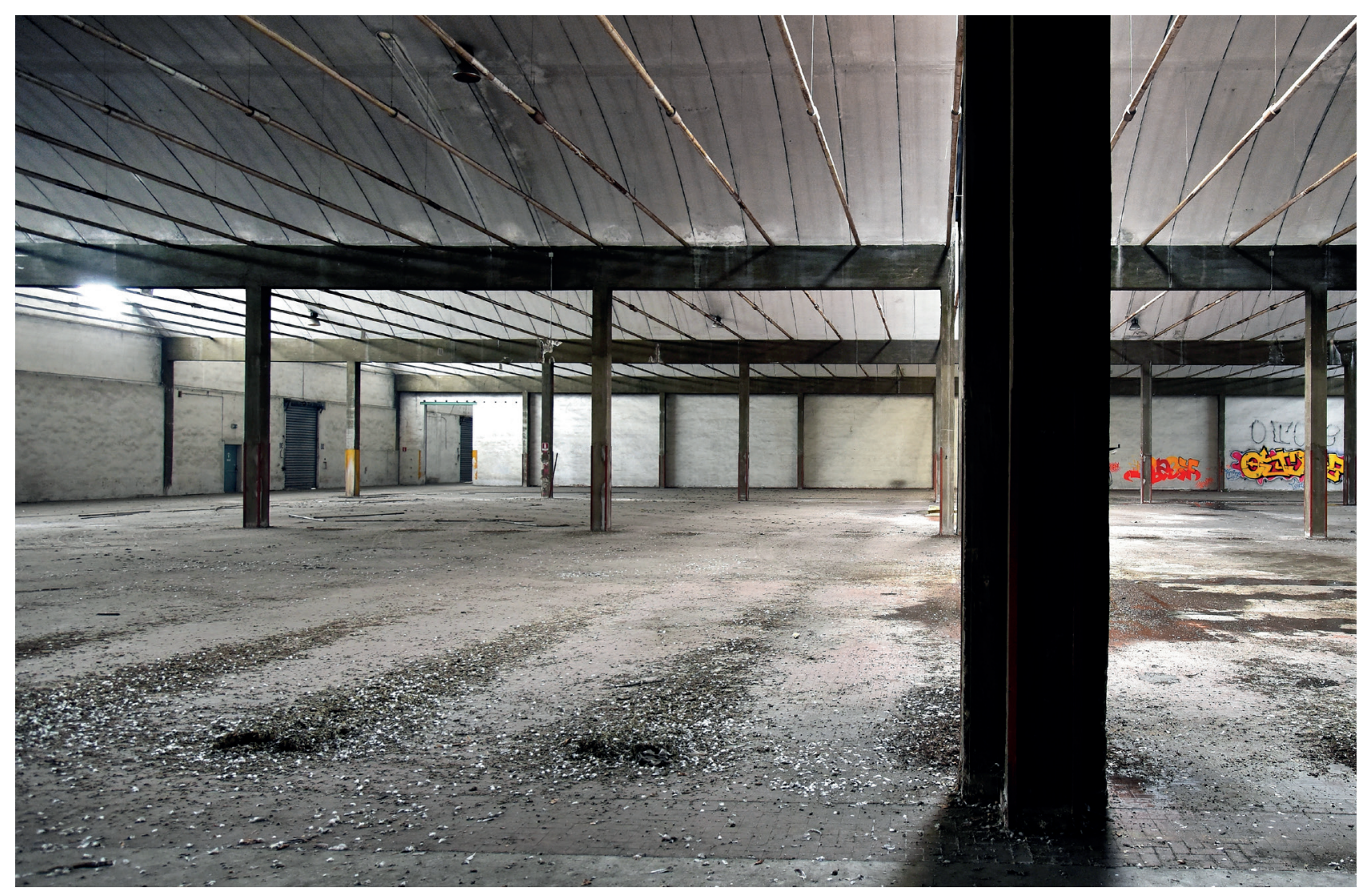

FIGURE 9: The Miralanza former storages in Padua, Italy (photo by S. Antoniadis, 2019).

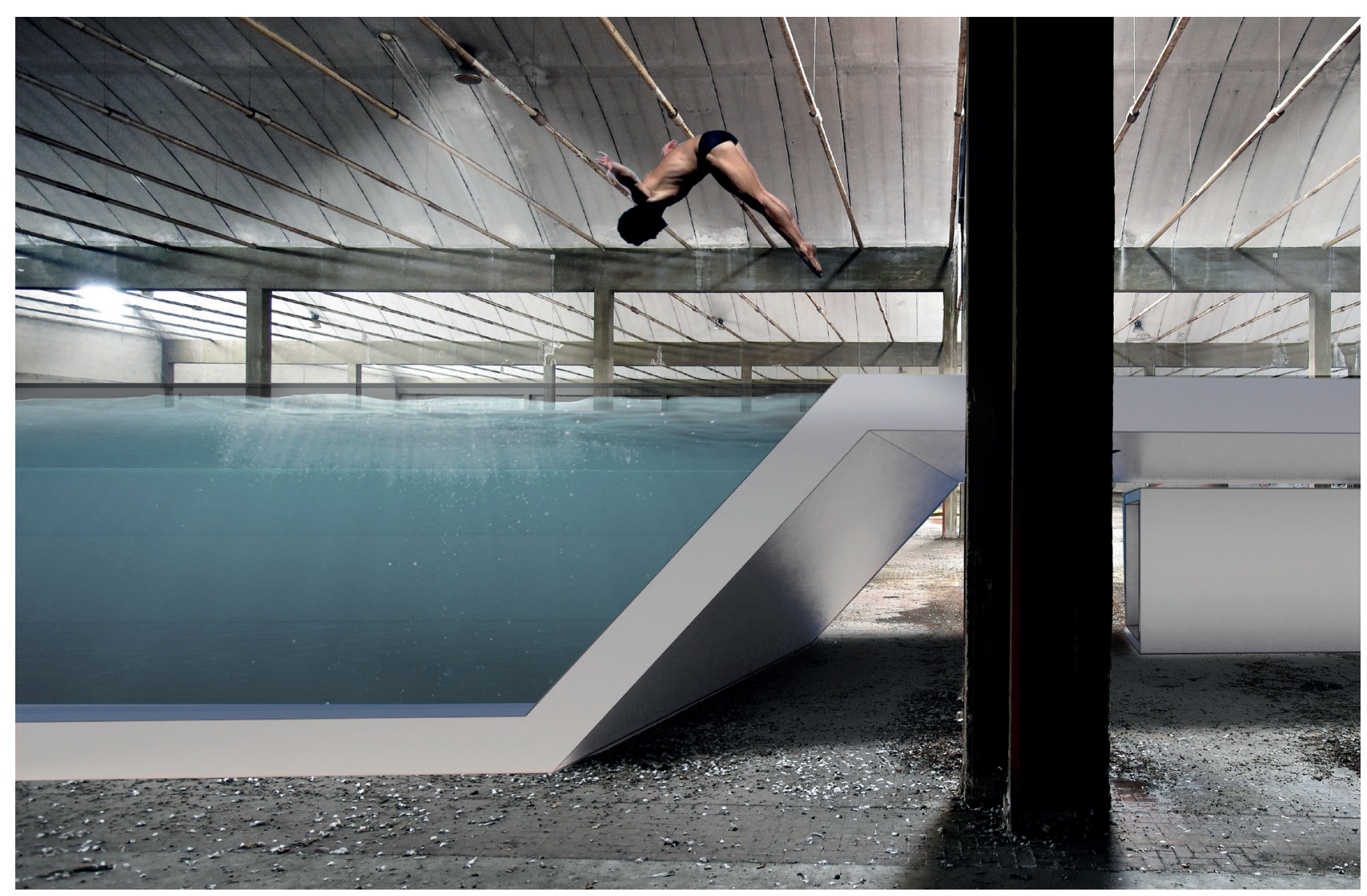

FIGURE 10: Transformation scenario for the Miralanza former storages (image by iWRECKS, 2019). 


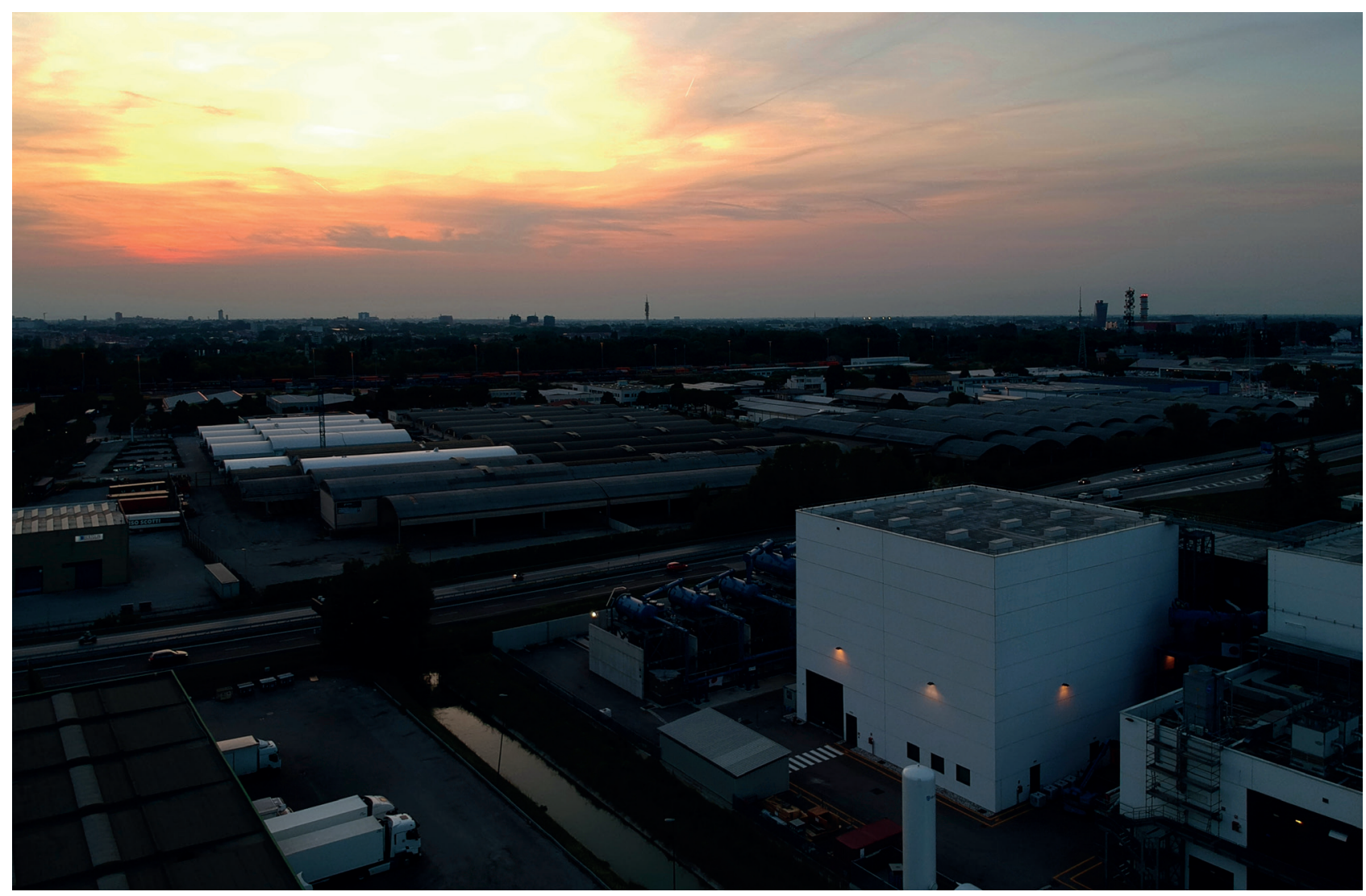

FIGURE 11: The Miralanza former storages in Padua, Italy (photo by L. Siviero, 2019).

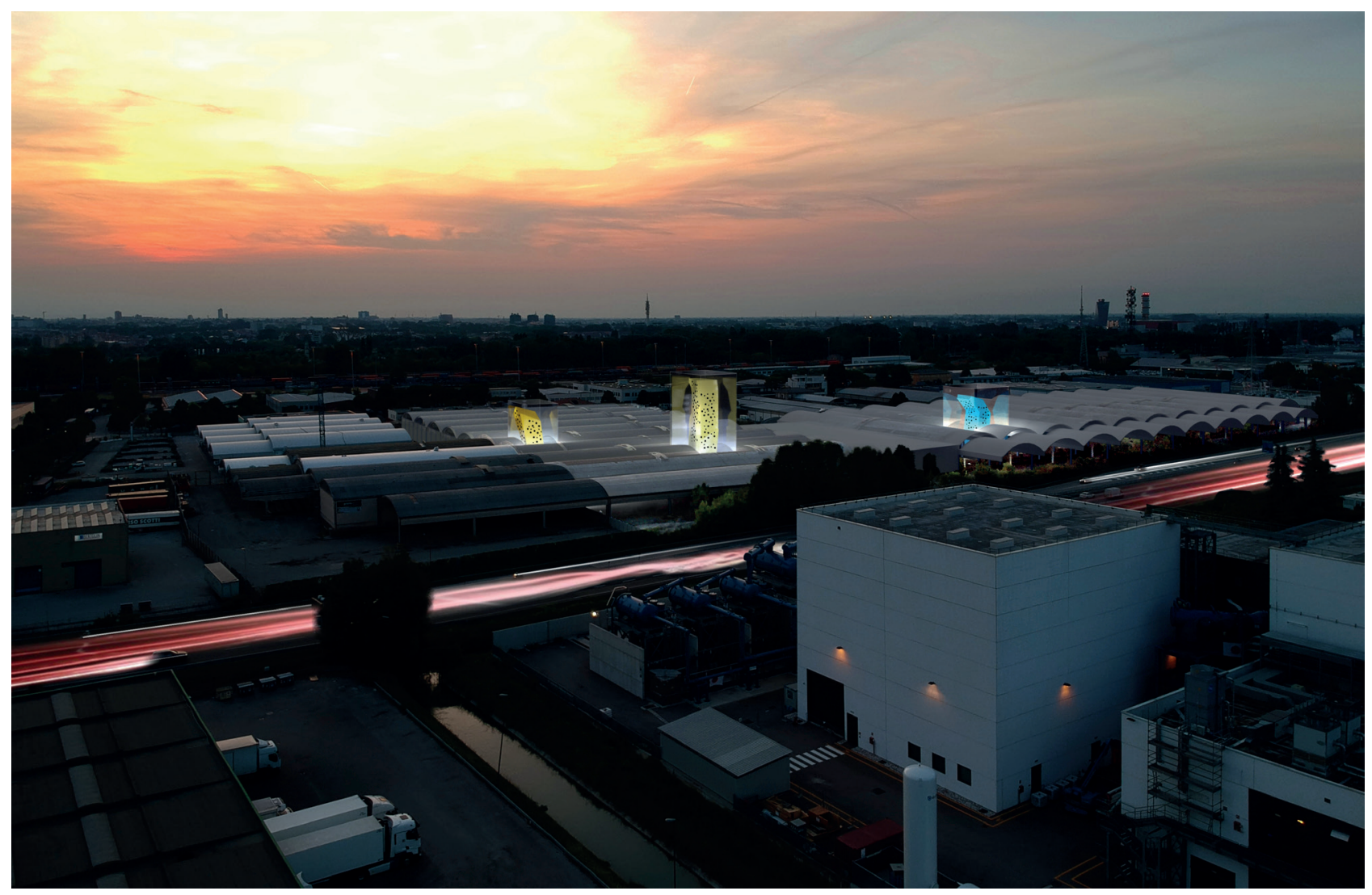

FIGURE 12: Transformation scenario for the Miralanza former storages (image by iWRECKS, 2019). 


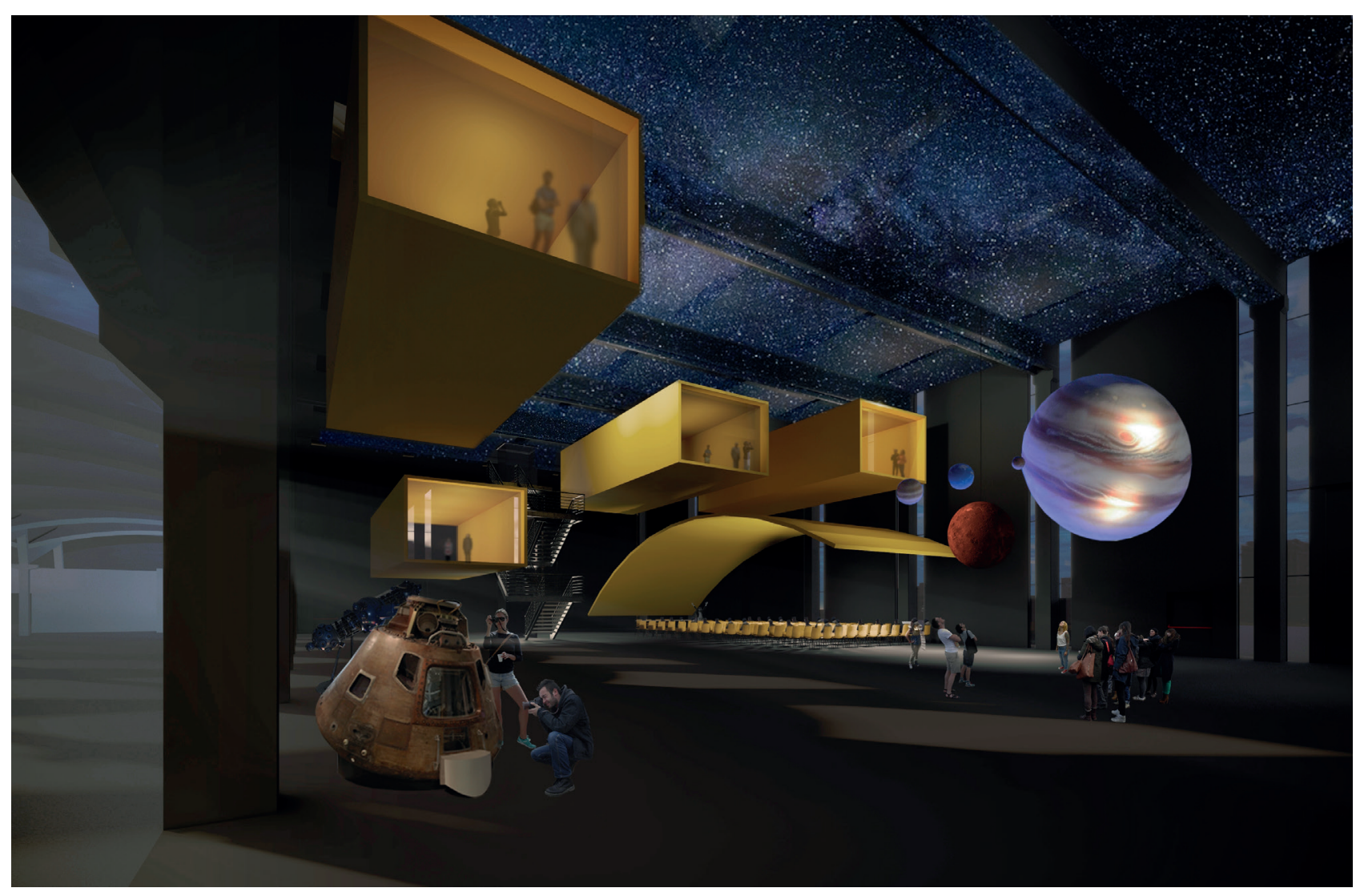

FIGURE 13: Transformation scenario for the SIT shed in Padua, Italy (image by iWRECKS, 2019).

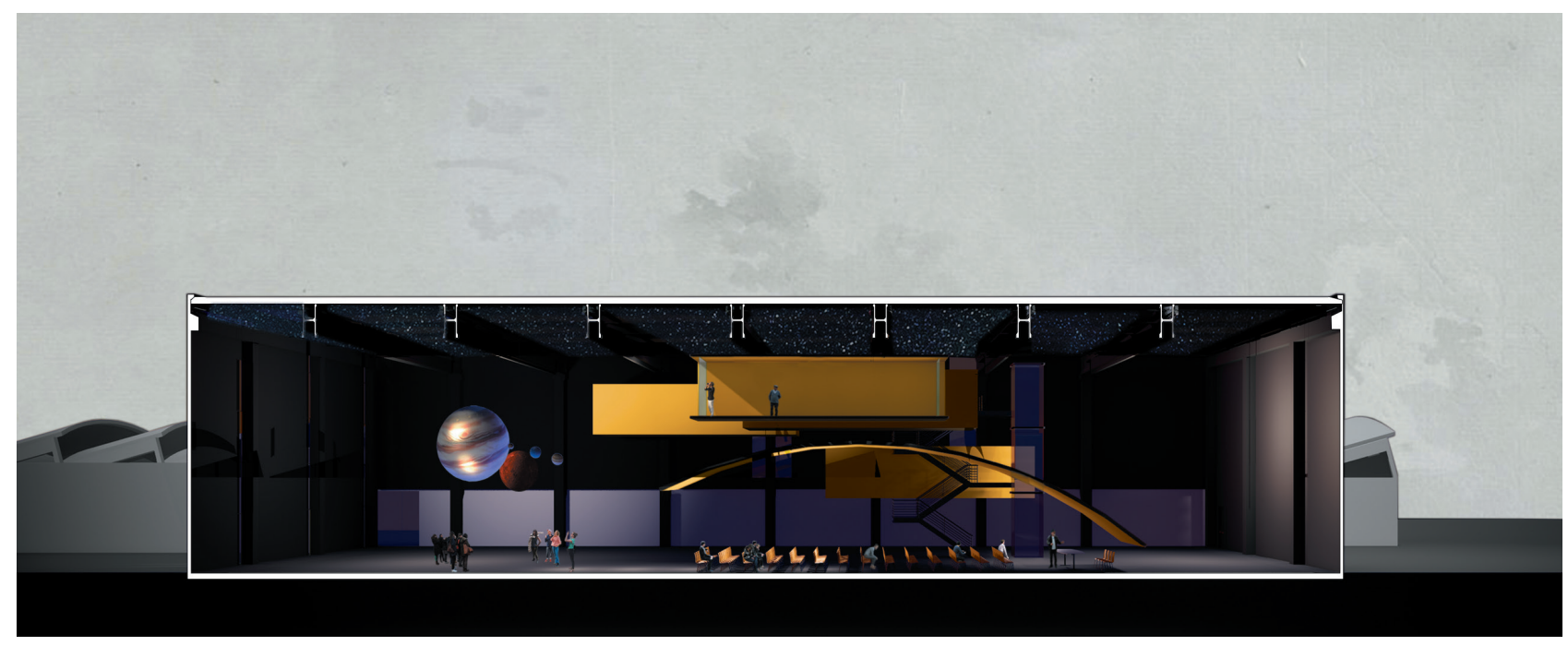

FIGURE 14: Transformation scenario for the SIT shed in Padua, Italy; section (image by iWRECKS, 2019).

as to improve an active awareness of contemporary landscape, with its failings but also challenges and potentials it affords. Last, but not least, such wrecks can be transformed even taking waste production and management into account: regarding abandoned industrial hangars as potential sources of so-far-not-foreseen transformations would mean a sharp cut in the number of buildings to be demolished - since written down as "unusable" - (and therefore in the amount of rubble). On the other hand, "cities have become very significant centres of consumption and transformation of resources [...] something that requires a dramatic rethinking about the energy systems that currently support our cities, but also the general organization and planning of urban areas towards sustainable forms." (Rosales-Carreon, 2018) Barring "refusing" progress - which is obviously unacceptable -, bearing in mind ours is a circular economy, "rethinking" is truly the first of viable strategies ${ }^{11}$. 


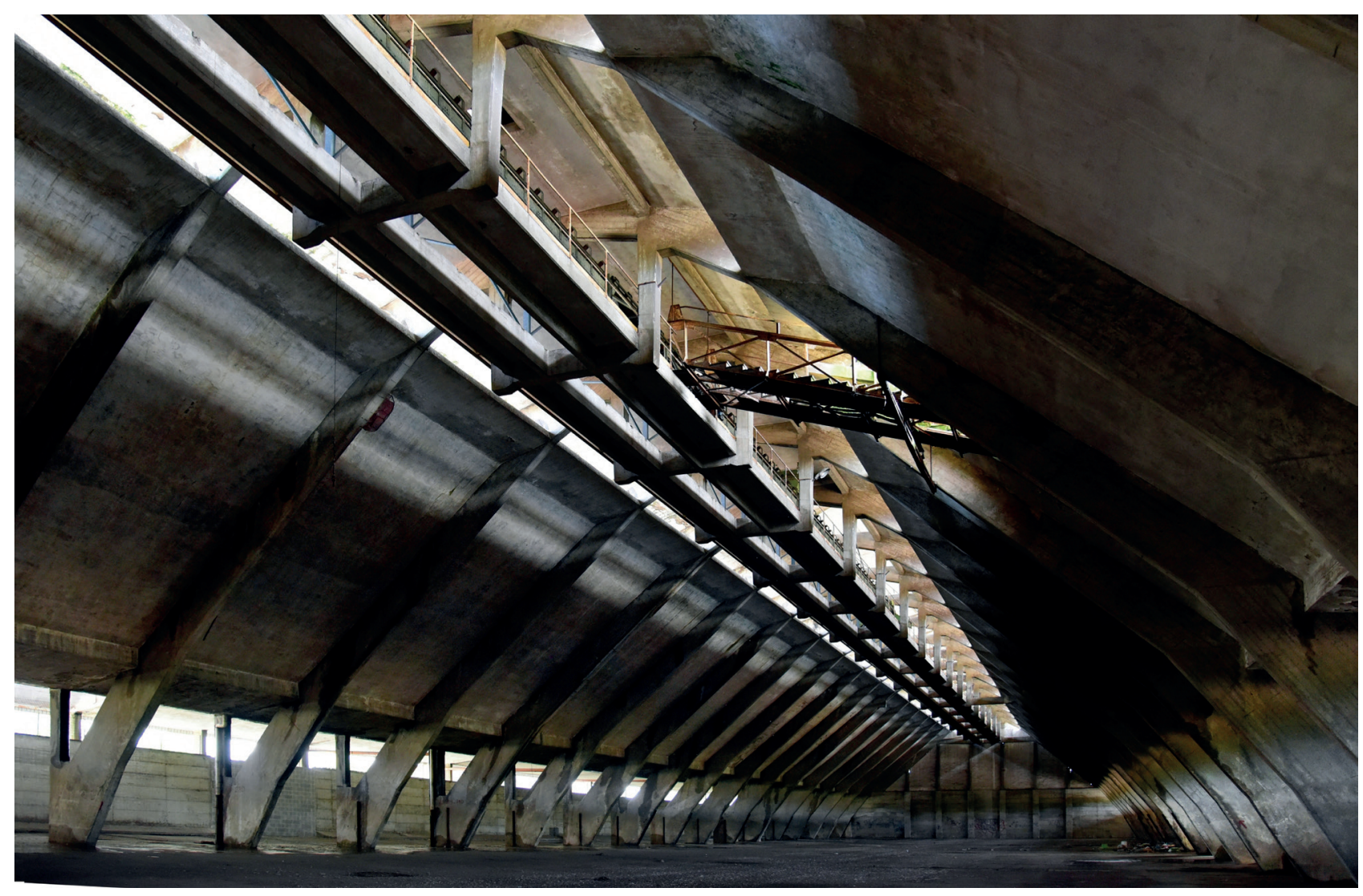

FIGURE 15: The Montedison former storehouse (the "Basilica") in Legnago, Verona, Italy (photo by S. Antoniadis, 2019).

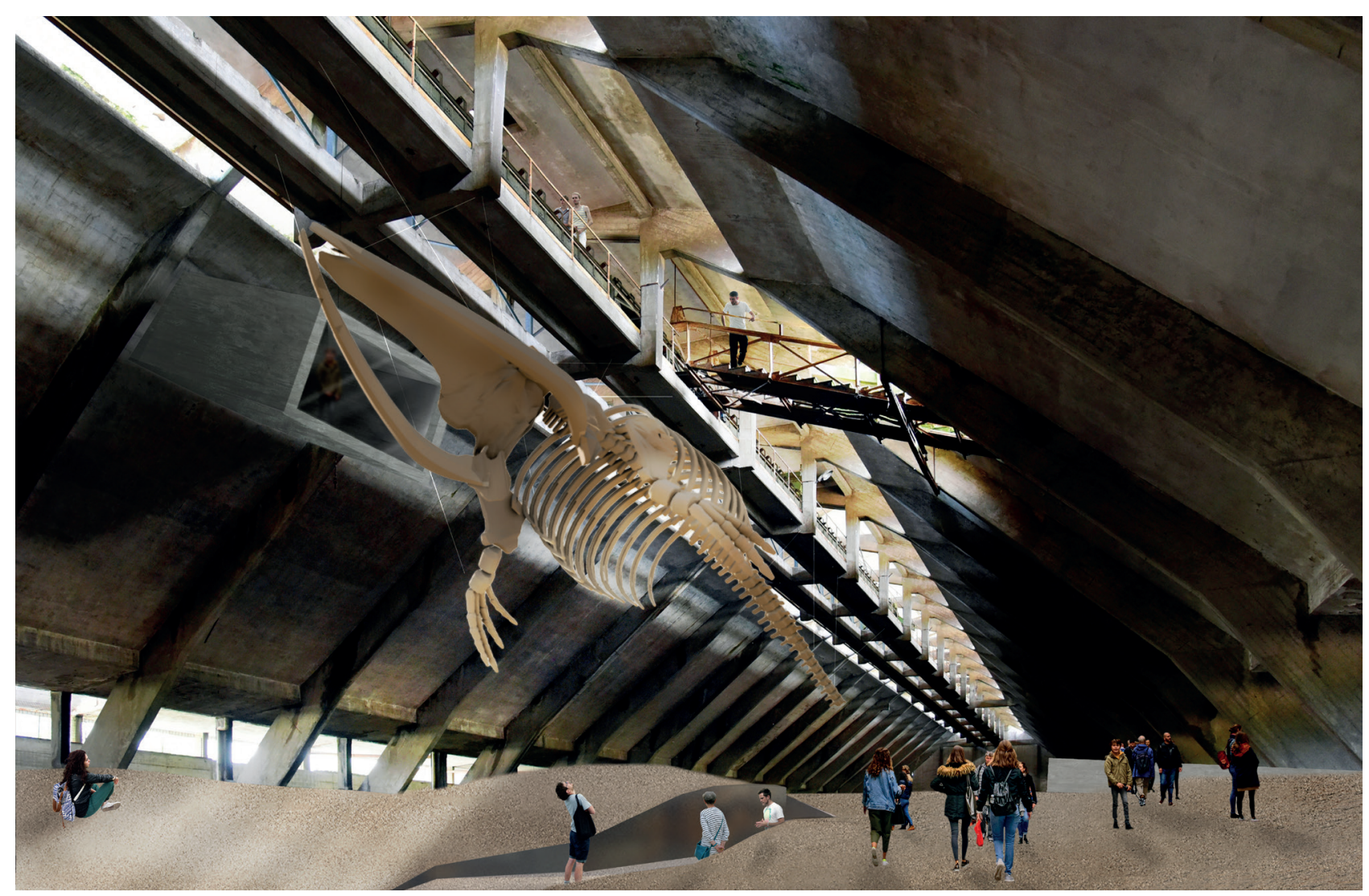

FIGURE 16: Transformation scenario for the Montedison former storehouse (image by iWRECKS, 2019). 


\section{ACKNOWLEDGMENTS}

This research has been funded by the Regional Operative Programme (ROP) European Social Fund (ESF) 'Veneto' 2014-2020, DGR n. 11 05/01/2018 (duration: Oct 15 th 2018 - Oct $14^{\text {th }} 2019$ (365 days) and involved three universities (University of Padua, IUAV University of Venice and University of Lisbon), and coordinated by Luigi Stendardo as P.I. (Please see note n. 2 for a complete description).

\section{REFERENCES}

Antoniadis, S., Redetti, E., 2019. (ed.), iWRECKS. Questioni, metodi, scenari di trasformazione per i relitti industriali. Padova: II Poligrafo. Agenzia del Territorio, 2019. Rapporto immobiliare 2019.

Rosales-Carreon, J., 2018. "The circularity in the built environment", in SUM 2018. $4^{\text {th }}$ Symposium on Urban Mining and Circular Economy Proceedings. Padova: CISA Publisher.
Bennett, L., 2017. Forcing the empties back to work? Ruinphobia and the bluntness of law and policy. In: Henneberry, J., (ed.). Transience and permanence in urban development. Hoboken, $\mathrm{NJ}$ : Wiley, pp. 17-30.

Brito-Henriques, E., 2017. Arruinamento e regeneração do espaço edificado na metrópole do século XXI: O caso de Lisboa. Eure, 43(128), pp. 251-272.

Rli, 2015. Circular economy. From intention to implementation. Council for the Environment and Infrastructure (Rli), The Hague.

Langston, C., Wong, F. K. W., Hui, E. C. M., \& Shen, L., 2008. Strategic assessment of building adaptive reuse opportunities in Hong Kong. Building and Environment, 43(10), pp. 1709-1718.

Sassi E., Vismara F., Ossanna Cavadini N., Acebillo J., 2007. Industrial buildings: Survey, analysis and evaluation of the conversion potential of disused industrial buildings in Ticino. Mendrisio $(\mathrm{CH})$ : i.CUP-Academy of Architecture USI Mendrisio.

Slade, G., 2006. Made to break: technology and obsolescence in America. Cambridge: Harvard University Press, 2006.

Packard, V., 1960. The Waste Makers. New York: David McKay Company, INC.
${ }^{1}$ Regional Operational Programme 'Veneto' 2014-2020, DATA_Developing Abandoned Transurban Areas, DGR n. 2216 13/12/2016, project code 2105114-2216-2016, funded by ESF. Steering Board: Stendardo L. (P.I.), De Marchi M., Giordano A., Lavagnolo M.C., Savino M.. Research Fellows: Antoniadis S., Barbato D., Malesani R., Pettoello G., Pristeri G., Redetti E.; Partner Companies: Archetipo, Federico Gianoli, LTS-Land Technology and Systems, Orienta+Trium, CZ Studio Associati, Favaro1, REAG Real Estate Avisory Group, Impresa Costruzioni Edili Garbo, Ravagnan, ACMO, Advertendo, Pallino \& Co. Network Partners: Fórema, Confindustria Padova, Associazione Centro Studi Usine.

${ }^{2}$ Regional Operational Programme 'Veneto' 2014-2020, iWRECKS_Industrial Wrecks: Reusing Enhancing aCKnowledging Sheds, DGR n. 11 05/01/2018, project code 2105-59-11-2018, funded by ESF. Steering Board: Stendardo L. (P.I.), Dias Coelho C., D'Acunto G., Lavagnolo M.C., Savino M.. Research Fellows: Antoniadis S., Bernardello R., Malesani R., De Stefani E., Redetti E. Junior Research Fellows: Borin P., Gonzalez-Libreros J., Pristeri G., Siviero L. Spera R.; Visiting Fellows: Padrão Fernandes S., Silva Leite J., dos Reis Costa P.; Partner Companies: Archetipo, Arcoplan, Cimolai, Contec, Duff\&Phelps Reag, Dal Zotto, Eco Avant-Garde, Expin, LTS-Land Technology \& Services; Network Partners: Universidade de Lisboa, Università luav di Venezia, Assindustria Venetocentro, ZIP - Consorzio Zona Industriale e Porto Fluviale di Padova, AIAPP - Associazione Italiana di Architettura del Paesaggio, Centro Studi Usine, Fórema.

${ }^{3}$ no. 14 Regional Law, $6^{\text {th }}$ June 2017 "Norms concerning curbing soil consumption and modifications of the no. 11 Regional Law, 23 $3^{\text {rd }}$ April 2004 Norms regarding monitoring land and landscape".
${ }^{4}$ SIT Group - Società Italiana Termomeccanica "La Precisa" (Italian Thermomechanical Society).

${ }^{5}$ Work signed by Paduan architect Giuseppe Davanzo (1921-2007), resorting to pre-fabricated technology in 1965-68 and abandoned soon afterwards.

${ }^{6}$ It was suggested by Oxway and Corriere della Sera and taken up by several Italian universities, research and professional groups: its aim was to prevent the 2015 Milan Universal Exposition site from becoming just a huge area fallen into disuse.

${ }^{7}$ Sapir-Whorf hypothesis, from the names of the linguist and anthropologist Edward Sapir (1884-1939) and of his henchman Benjamin Lee Whorf (18971941), maintains that not only each individual's cognitive development is influenced by the language he/she speaks, but even that language determines thought and therefore existence itself.

${ }^{8}$ AMAT Srl - Technoshapes for Industry.

${ }^{9}$ MTB stands for Mountain/Trials Bike.

${ }^{10}$ It is appropriate to point out that buildings regarded as "industrial archaeology" are by no means the main object of our research, since the subject has been widely dealt with, enjoys a sizable literature and well-known approaches have already been analysed. This work deals with the numberless recently-built hangars on which regional arguments are focused, as well as with soil consumption and the challenges posed by upgrading.

${ }^{11}$ Refuse, Rethink, Reduce, Reuse, Repair, Refurbish, Remanufacture, Repurpose, Recycle, Recover are the Hierarchical R-ladder. From Rli (2015). Circular economy. From intention to implementation. Council for the Environment and Infrastructure (Rli), The Hague. 